\title{
Hashimoto's Thyroiditis-Associated Acute Renal Failure and Pitfalls of eGFR Interpretation in Thyroid Diseases
}

\author{
Frank-Peter Tillmann ${ }^{1,2}$, Ana Harth ${ }^{1}$, Achim Jörres ${ }^{1}$ \\ ${ }^{1}$ Department of Medicine I, University Witten/Herdecke, Medical Center Cologne-Merheim, Germany \\ ${ }^{2}$ Nephrological Centres Münsterland, Ibbenbüren, Germany
}

Received: $16 / 05 / 2021$

Accepted: 20/05/2021

Published: $22 / 06 / 2021$

How to cite this article: Tillmann FP, Harth A, Jörres A. Hashimoto's thyroiditis-associated acute renal failure and pitfalls of eGFR interpretation in thyroid diseases. EJCRIM 2021;8: doi:10.12890/2021_002645.

Conflicts of Interests: The authors declare there are no competing interests.

This article is licensed under a Commons Attribution Non-Commercial 4.0 License

\section{ABSTRACT}

The authors describe a patient with severe hypothyroidism due to Hashimoto's thyroiditis and describe the pitfalls of estimated glomerular filtration rate interpretation in such cases.

\section{LEARNING POINTS}

- Manifest hypothyroidism can lead to a functional reduction in glomerular filtration rates (GFRs).

- Restoration of a normal thyroid stimulating hormone (TSH) will also restore kidney function.

- Cystatin C-based GFR formulas will overestimate renal filtration rates in cases of hypothyroidism and underestimate GFRs in cases of hyperthyroidism.

\section{KEYWORDS}

Hashimoto, thyroiditis, AKIN, cystatin C, eGFR

\section{INTRODUCTION}

Thyroid dysfunction is associated with impaired renal function. The interpretation of cystatin C-based glomerular filtration rate (GFR) estimates should be evaluated differently depending on the hormonal situation. In cases of renal dysfunction of unknown origin, thyroid dysfunction should be considered in the differential diagnosis. We describe a case of difficult interpretation of laboratory results in autoimmunogenic thyroiditis with manifest severe hypothyroidism.

\section{CASE DESCRIPTION}

The 52-year-old patient present to a nephrologist for further diagnosis of an unclear elevation in creatinine value. The patient's medical history noted decreasing sports performance but was otherwise unremarkable. No relevant previous diseases or a conspicuous family history were reported. The physical examination was unremarkable. Blood pressure was $111 / 71 \mathrm{mmHg}$. The patient was not taking any medication at the time of the first examination. Initial laboratory results on the day of the first examination included the following pathological findings: creatinine $1.39 \mathrm{mg} / \mathrm{dl}$ (normal range 0.2-0.9), estimated GFR (eGFR) according to the CKD-EPI formula $58 \mathrm{ml} / \mathrm{min} / 1.73 \mathrm{~m}{ }^{2}$ BSA and sodium $134 \mathrm{mmol} / \mathrm{I}$ (normal range 136-145). All other initial laboratory parameters were within normal ranges (blood count, potassium, chloride, 
calcium, phosphate, uric acid, cANCA and pANCA titres, parathyroid hormone, calcidiol levels, ANAs, urine status with sediment, albumin to creatinine ratio in spot urine, and cystatin $C$ with an eGFR of $94 \mathrm{ml} / \mathrm{min} / 1.73 \mathrm{~m} 2 \mathrm{BSA})$. Sonography of the abdomen including the kidneys did not reveal any pathological findings (Fig. 1). A further search for the cause of the discrepancy between the creatinine-based and the cystatin C-based eGFR revealed unremarkable values for CRP, lipid values, HbA1c, ferritin, alkaline phosphatase, liver panel, and total protein with protein electrophoresis in the serum. However, a massively elevated TSH value of $157 \mu \mathrm{lU} / \mathrm{ml}$ (normal range 0.27-4.20) was found. Further thyroid diagnostics showed sonographically undetectable thyroid tissue (Fig. 2). Determination of thyroid-specific autoantibodies revealed elevated thyroid autoantibodies of $106 \mathrm{U} / \mathrm{ml}$ (normal range <34) with normal values for TSH receptor and thyroglobulin autoantibodies, so the diagnosis of hypothyroidism in autoimmunogenic thyroiditis of the Hashimoto type was made. Over the course of several months, oral thyroid hormone substitution with increasing doses of L-thyroxine was followed by normalization of TSH and creatinine (Table 1).
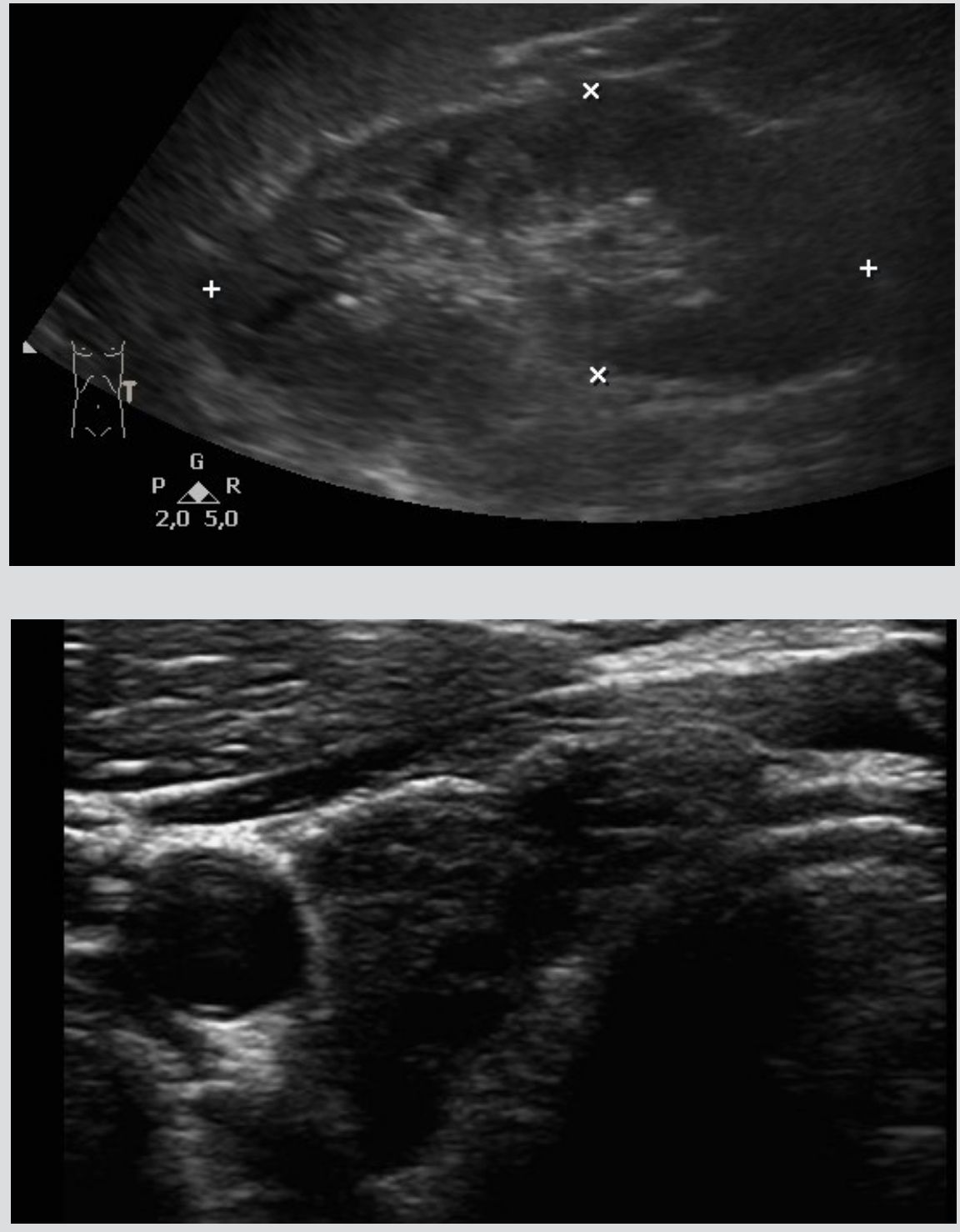

Figure 1. Sonography of the left kidney showing normal parenchyma in a patient with severe hypothyroidism and an eGFR according to the CKD-EPI formula of $58 \mathrm{ml} / \mathrm{min} / 1.73 \mathrm{~m}^{2} \mathrm{BSA}$

Figure 2. Sonography of the right thyroid lobe showing largely destroyed thyroid parenchyma with degenerative cysts in a patient with severe hypothyroidism and an eGFR according to the CKD-EPI formula of $58 \mathrm{ml} / \mathrm{min} / 1.73 \mathrm{~m}^{2} \mathrm{BSA}$

\section{DISCUSSION}

Autoimmunogenic thyroiditis of the Hashimoto type was diagnosed as the cause of the initially reduced renal function according to the CKD-EPI formula. At initial presentation, a discrepancy between the creatinine and cystatin C-based GFR measurements of approx. 40 $\mathrm{ml} / \mathrm{min} / 1.73 \mathrm{~m}^{2}$ BSA was noticed. Although a correlation between both laboratory markers and renal function has been described in the literature, the pitfalls of eGFR interpretation in cases of thyroid disease with discrepant results between creatinine-based and cystatin 


\begin{tabular}{|l|l|l|l|l|}
\hline Months after diagnosis & 0 & 1 & 4 & 6 \\
\hline Creatinine, mg/dl & 1.39 & 1.21 & 1.06 & 1.09 \\
\hline $\begin{array}{l}\text { eGFR (creatinine), } \\
\text { ml/min/1.73 m2 BSA }\end{array}$ & 58 & 69 & 81 & 78 \\
\hline Cystatin C, mg/l & 0.82 & 0.83 & - & 0.99 \\
\hline $\begin{array}{l}\text { eGFR (cystatin C), } \\
\mathrm{ml} / \mathrm{min} / 1.73 \mathrm{~m} 2 \mathrm{BSA}\end{array}$ & 94 & 93 & - & 76 \\
\hline TSH, $\mu \mathrm{lU} / \mathrm{ml}$ & 157 & 130 & 26 & 1 \\
\hline
\end{tabular}

Table 1. Clinical evolution of laboratory parameters from diagnosis to final treatment

C-based formulas are largely under-recognized. A hypothyroid metabolic situation can affect the kidney through direct effects on glomerular and tubular function as well as indirect effects through changes in cardiac and vascular function or alteration of the renin-angiotensin system $^{[1-3]}$. Population-based studies in humans have demonstrated an association between elevated TSH levels and lower GFR, and thus a higher prevalence of chronic kidney disease, independent of age, sex, BMI, smoking status and other comorbidities ${ }^{[4,5]}$. It is of particular importance that the association between hypothyroidism and reduced GFR is based not only on laboratory calculations of mathematical formulas, but also on direct measurements of GFR using inulin- or 51Cr-EDTA-based methods ${ }^{[6]}$. Hyponatraemia and impaired excretion of free water are equally common complications of manifest hypothyroidism. Reduced GFR, reduced renal sodium reabsorption, a relative increase in vasopressin secretion or an increase in the vasopressin sensitivity of the tubular system have been described as causes ${ }^{[7]}$.

In contrast, the validity of cystatin C-based determination of GFR seems to be reduced in manifest hypothyroid situations. Cystatin C belongs to the group of protease inhibitors. It is synthesized by nucleated cells, filtered in the glomerulus, and reabsorbed in the proximal tubule system ${ }^{[8]}$. In manifest hypothyroidism, as in our case, cystatin C levels appear to be reduced, indicating a falsely high GFR, whereas manifest hyperthyroidism results in falsely low GFR values ${ }^{[9,10]}$.

As in our case, adequate hormone replacement therapy leads to normalization of TSH, creatinine and cystatin $\mathrm{C}^{[10]}$. However, every clinician should be aware of the different interpretations of cystatin C-based laboratory results depending on current thyroid function, not least to prevent unnecessary diagnostic or inappropriate therapeutic measures. In addition, nephrological evaluation of reduced renal function should routinely include an examination of thyroid function.

\section{REFERENCES}

Iglesias P, Diez JJ. Thyroid dysfunction and kidney disease. Eur J Endocrinol 2009;4:503-515.

Mariani LH, Berns JS. The renal manifestations of thyroid disease. J Am Soc Nephrol 2012;1:22-26.

Dousdampanis P, Trigka K, Vagenakis GA, Fourtounas C. The thyroid and the kidney: a complex interplay in health and disease. Int J Artif Organs $2014 ; 1: 1-12$.

Lo JC, Chertow GM, Go AS, Hsu CY. Increased prevalence of subclinical and clinical hypothyroidism in persons with chronic kidney disease. Kidney Int 2005;3:1047-1052.

Sun MT, Hsiao FC, Su SC, Pei D, Hung YJ. Thyrotropin as an independent factor of renal function and chronic kidney disease in normoglycemic euthyroid adults. Endocr Res 2012;3:110-116.

6. Karanikas G, Schutz M, Szabo M, Becherer A, Wiesner K, Dudczak R, et al. Isotopic renal function studies in severe hypothyroidism and after thyroid hormone replacement therapy. Am J Nephrol 2004;1:41-45.

7. Montenegro J, Gonzalez O, Saracho R, Aguirre R, Gonzalez O, Martinez I. Changes in renal function in primary hypothyroidism. Am J Kidney Dis 1996;2:195-198.

8. Laterza OF, Price CP, Scott MG. Cystatin C: an improved estimator of glomerular filtration rate? Clin Chem 2002;48:699-707.

9. Manetti L, Pardini E, Genovesi M, Campomori A, Grasso L, Morselli LL, et al. Thyroid function differently affects serum cystatin C and creatinine concentrations. J Endocrinol Invest 2005;28:346-349.

10. Fricker M, Wiesli P, Brändle M, Schwegler B, Schmid C. Impact of thyroid dysfunction on serum cystatin C. Kidney Int 2003;63:1944-1947. 